\title{
CÓMO PRESENTAR HOY A LOS JÓVENES LA VOCACIÓN CRISTIANA
}

DOI: https://doi.org/10.52039/seminarios.v51i177.702

Autor: Hilário Dick. Sacerdote Jesuita. Decano de la facultad de Juventud de la Universidad de Porto Alegre. San Leopoldo (Brasil).

\section{EL JOVEN FRENTE A LA VOCACIÓN CRISTIANA}

Para el desarrollo de nuestra pequeña reflexión sobre el tema vamos a resaltar cierto malestar con el uso del vocabulario, una postura pedagógica con sus crisis y respuestas, para resaltar dos instrumentos.

\section{A) Incomodidad}

1. Todos los que estamos aquí somos, de una u otra forma, presentadores/as de la vocación cristiana a los jóvenes. Pero, confieso cierto incomodidad por el uso del verbo "presentar". Claro que podemos "presentar" personas, proyectos... "Presentar" la vocación cristiana sería algo así 
como si presentáramos un producto nuestro, buscando expresiones convincentes de "marketing"... Como si la vocación cristiana estuviera en venta en algún supermercado, colocada junto a decenas de productos semejantes, dependiendo de la ley de la oferta y la demanda. Hay otros verbos mejores. El primero que me viene a la cabeza es "anunciar". Todos tenemos presente el Documento "Evangelii Nuntiandi", de Pablo VI. "Anunciar" es más pastoral, más evangélico, más teológico... Otro verbo que se me ocurre es "proponer". Cuando nos movemos en el mundo de la fe, estamos frente a una "propuesta" que pide una "respuesta"; ante un don que nos es dado gratuitamente. Trabajar en el mundo de la vocación significa estar metido en el mundo de una propuesta que es necesario "revelar", que es necesario "despertar". Se trata de "despertar" algo que ya existe, algo que duerme, algo que está escondido, algo que -más que presentación- supone aceptación, conciencia, convencimiento, conversión. El llamado no es algo provocado por nosotros; el llamado vive en la persona; el llamado es la forma deseada por Dios para que cada cual viva su felicidad. Una felicidad que, también, es propuesta tal vez esperando ser despertada.

2. No es, sin embargo, solamente el "verbo" del enunciado lo que molesta. Molesta el hecho de intentar saber en qué espacio se ubica el contenido de "Como presentar a los jóvenes hoy la vocación cristiana". ¿En qué espacio se mueve la cuestión formulada? Uno de estos espacios puede ser la "didáctica", doctrina de la enseñanza y del método. "Saber" presentar... Saber usar dinámicas, estrategias, instrumentos que llamen la atención, que involucren, que convenzan. Es importante que la presentación sea agradable, que el producto tenga "miel". No se abraza un modo de ser que no sea de felicidad, de buena apariencia, de realización humana. Presentar la vocación cristiana a los jóvenes es algo didáctico.

Otro espacio es el "pedagógico". ¿Cómo llevar, dentro de un proceso, la presentación de la vocación cristiana a los jóvenes? Supone algo más que didáctica. Supone involucrar, acompañamiento, descubrimiento personal reflejo, llevando hasta una decisión. Pensamos en el proceso de educación en la fe con sus exigencias "misteriosas" porque allí se encuentra el misterio de Dios dialogando con el misterio de la persona. Pensamos en las necesidades que esto supone: p. ej. conocer a las personas con las que trabajamos. Así como supone familiaridad con el misterio de Dios, es 
evidente que también tener comprensión del misterio del joven. Una buena antropología teológica juvenil.

El servicio de "despertar la vocación cristina en el joven" se mueve, en tercer lugar, en el espacio "político". La vocación es una propuesta para un mundo concreto, para una iglesia concreta, para personas moviéndose en modos concretos de vivir la realidad humana, familiar, religiosa y social. Estamos hablando de los "escenarios" de Iglesia, de los escenarios de sociedad, de familia y de la vida religiosa. Los escenarios traducen en el concreto de la vida el todo de nuestro credo, también el credo político. Con nuestro modo de ser revelamos -"presentamos"- los escenarios en los que nos movemos. El contenido de nuestras reflexiones debe ser, por eso, político. Proponemos un modo total de ser y de vivir.

Con eso llegamos a un cuarto espacio del contenido: el "teológico". ¿El contenido de la presentación de la vocación cristiana al joven será teológico? Por un lado se presenta todo lo que significa el "llamado" de Dios $y$, por otro, lo divino que es real en el joven. Hay hechos que certifican que el contenido del servicio de animación vocacional se mueve fuertemente en ese espacio teológico. La realidad del llamado divino, en Dios, es tan fuerte que nos olvidamos de trabajar lo divino que se encarna en el joven. Parece que la Pastoral Juvenil trata del joven y la Pastoral Vocacional del llamado... El joven es mucho más que un llamado "externo", "divino", "misterioso" desde afuera; desde su interior específico, juvenil, el joven es no solamente una realidad psicológica, sociológica, histórica, cultural o política; es, igualmente, una realidad teológica que es importante comprender, revelar y desarrollar a partir de su experiencia vital. En este espacio se mueve la vocación.

3. Otro malestar proviene del término "vocación cristiana". a) Es verdad que vocación significa un llamado para un determinado modo radical de vivir la felicidad. ¿No sería mejor hablar de vocacionalidad (sin adjetivo)? Vocacionalidad como algo que se revela, se descubre y se vive como forma de ser feliz? b) la vocación es un don, es una gracia que nos ha sido dada por el bautismo. Fundamentados (inmersos) en Cristo aprendemos que todo cristiano, para ser feliz, es llamado a ser (en la terminología de la tradición) sacerdote, profeta y rey. Cualquiera que sea la forma de vivir nuestra fe en el mundo, no podemos dejar de ser celebrantes del mundo (sacerdotes), especialmente del mundo que nos es más cercano, en 
sus organismos intermediarios), haciendo que la vida sea, siempre, una fiesta; analistas de la vida (profetas), anunciando la vida y denunciando lo que lleva a la muerte. No podemos vivir sin hacer, cotidianamente, análisis de coyuntura. Es vocación de todos saber leer los signos de los tiempos; constructores de comunidad (reyes), esto es, políticos. Hablar de la vocación cristiana es hablar de éstas dimensiones recibidas por el don del bautismo. Es la vocación cristiana...

4. El último malestar se refiere a una pregunta: Si queremos hablar de "Como presentar a los jóvenes, hoy, la vocación cristiana", ¿vamos hablar del qué? Como Pablo VI, vamos hablar a) ¿del contenido de la evangelización, esto es, del testigo del amor del Padre revelado en su Hijo en el Espíritu? ¿de la salvación en Jesucristo? ¿del mensaje liberador que interpela toda nuestra vida? ¿de la liberación fundada en el Reino de Dios, todo eso traducido para la realidad juvenil? b) ¿de los caminos de la evangelización, como el testimonio, la plegaria, la liturgia, la catequesis, el uso de los medios de comunicación, del papel de los sacramentos, de la religiosidad popular, pensando siempre en la realidad de los jóvenes de hoy? c) ¿de los destinatarios de la evangelización, esto es, de los jóvenes que están lejos, que no tienen educación religiosa, a los cuales no le gustan las instituciones, a los que participan en grupos o comunidades juveniles? d) ¿ de los obreros de la evangelización, insistiendo que somos una iglesia esencialmente misionera que debe usar un lenguaje juvenil, que sea abierta, que mire a los/as asesores/as de jóvenes como viviendo un ministerio específico sean laicos/as, sacerdotes o religiosos/as, que fomente en la juventud el espíritu de las misiones de jóvenes?

\section{B) Postura pedagógica}

Expresados estos malestares y procurando responder al desafío propuesto, optamos por una reflexión y una postura pedagógica, concluyendo con una afirmación en el campo instrumental.

\section{B1) Crisis}

Empezaremos por una visión "problemática", esto es, una visión que se confronta, inicialmente, con las grandes crisis de los jóvenes porque la 
"solución" se encuentra, también, en estos mismos espacios. En una perspectiva de formación integral de la persona, las crisis de los jóvenes se ubican en cinco grandes espacios:

1. La vivencia comunitaria. Es parte de la felicidad de todo joven la vivencia grupal. El descubrimiento del otro y de lo comunitario necesita ser atendido. Estamos viviendo una "era grupal", aunque nos lleven a pensar que estamos en una era del individuo comunicándose desde su computadora. Considerando p. ej. que una diócesis tenga 380 grupos juveniles de Iglesia y que este número significa $26,6 \%$ de los grupos existentes en esta diócesis, deben existir en esta diócesis cerca de 1.500 grupos (comunidades) diferentes de jóvenes. No poder participar el joven del "grupo" o no querer pertenecer al "grupo" es una fuente radical de crisis, tal vez rechazada, tal vez inconsciente, pero real. El grupo es el lugar de felicidad del joven. La experiencia radical de felicidad del joven (esto es, de lo divino que hay en él) se da en la vivencia comunitaria. Por eso es dramático, es antipedagógico, no es integradora una institución que no favorece el grupo o estamos en un contexto socioeconómico en el que la comunidad se torna casi un imposible o, se le dificulta con innumerables invitaciones al aislamiento.

2. La búsqueda de la integridad. Están en cuestión, en este caso, 1) la posibilidad de ser, de poseerse, de donarse en el amor (la personalización, descubriendo su misión en el mundo - vocacionalidad); 2) la posibilidad de convivir y de comunicarse (la socialización o la integración comunitaria); 3) la posibilidad de situarse y de comprometerse históricamente (la socialización y el espacio del ser político, concientizado); 4) la posibilidad de transcenderse (realizándose teológica y teologalmente); 5) la posibilidad de hacer y construir (la capacitación técnica). La ausencia de esta integridad suscita enormes crisis. Crisis que el propio joven quizás no sepa expresar, pero que experimenta.

3. La organización. Nadie es feliz si no vive de manera organizada, perteneciendo a alguna entidad que luche por los derechos de la sociedad. La mejor escuela de formación esta en la participación activa de una organización. La formación se da, prioritariamente, en la acción y no desde una postura teórica. El individuo se realiza en el colectivo, más amplio que lo familiar y la rueda de amigos. 
4. El trabajo con las diferencias. La única forma de descubrimiento de la identidad personal está en el descubrimiento de las diferencias. El estudiante se realiza como estudiante en el momento en que se acepta como estudiante y no como obrero. La afirmación de la identidad personal supone claridad sobre el diferente, esto es, de aquello que él no es. En la Pastoral Juvenil un debate serio se relaciona con trabajos en diferentes medios específicos, sintiéndose complementarios de una globalidad, de una organicidad. Lo orgánico, la globalidad no tiene peso si no hay claridad de las diferentes partes de su todo. El matrimonio más feliz es aquel que tiene conciencia de sus diversidades, cuando la tentación es decir que "pensamos lo mismo". Necesitamos encontrarnos en el diferente.

5. La vivencia feliz del acompañamiento. Persona feliz es aquella que en su individualidad se siente "acompañada", esto es, que puede buscar el sentido de su vida junto con el otro y la otra. No hemos sido creados para vivir solos: por eso nos casamos, por eso nos organizamos, por eso vivimos en comunidad, por eso oramos, por eso estudiamos etc. El acompañamiento puede tomar diferentes traducciones: necesidad del padre y de la madre, necesidad el educador, necesidad del director espiritual, necesidad de la revisión de vida en grupo, necesidad de reuniones etc. No querer ser "acompañado" no es traducción de una vivencia feliz. Ser tan autónomo que no se precisa del otro no es signo de felicidad.

\section{B2) Postura pedagógica}

Si estas son las grandes crisis de los jóvenes, la presentación de la vocación cristiana de los jóvenes debe responder a estas cinco interpelaciones radicales. "Radicales" porque nos llevan a la raíz de nuestro mensaje, de nuestra intervención y de nuestro rol de animadores de vocaciones en el corazón de la juventud. Se trata, por eso de:

a) Fomentar, creer, ser experto, acompañar, animar una linda, concreta y persistente vivencia comunitaria o de grupos juveniles. El grupo juvenil no pasó de moda. La vivencia grupal de los jóvenes es una necesidad para ellos. El grupo juvenil es el lugar de la felicidad del joven que desea descubrirse en su identidad. Aunque la globalización lleve al cultivo del individualismo, nunca en la historia hubo tantos grupos juveniles como 
actualmente. El fomento de la vivencia comunitaria pertenece al credo pedagógico y teológico de quién sueña con la posibilidad vocacional del joven. Hay que ser especialista en vida grupal con sus diferentes fenómenos; hay que estar con ellos en la práctica y en la postura pastoral. Dios habla más fuertemente en esas vivencias sistemáticas que en nuestros discursos de ofrecimiento teórico de un compromiso que no se concreta.

b) Entender, cultivar, tornar práctica, luchar, hacer de todo para que el joven viva un proceso de formación integral. Una formación integral está despierta para todas las dimensiones de la personalidad: personalización, socialización, vivencia teológica y teologal, dimensión política, vocacional y preparación técnica para diversas eventualidades, personales, grupales y masivas. La descripción pormenorizada de éstas dimensiones es un avance enorme que ha dado la Pastoral Juvenil Latinoamericana. En su integridad exige conocimiento, estudio, pedagogía, inserción en las diferentes realidades o momentos, etc. Ésta se encara, además, como un proceso que respeta la dinámica del joven y el dinamismo de la propia fe. En la vivencia de este proceso la posibilidad vocacional es fruto natural, ayudando al joven a que se descubra a sí mismo, relacionándose con el mundo, el otro, la naturaleza y Dios. La posibilidad vocacional también es un proceso. No ofrecemos al joven un discurso, sino una práctica integral y progresiva.

c) Ayudar a que el joven se encarne, lo más comprometidamente, en la realidad en la cual vive, descubriendo allí su identidad y su forma de realizarse. Hablamos, por eso, de inserción en los organismos intermediarios de la sociedad civil, hablamos de pastorales específicas de juventud, hablamos de encarnación, hablamos de la riqueza de las diferencias, hablamos de juventudes, de género... El descubrimiento de la identidad no es un proceso tranquilo y, al comienzo, nada agradable para el joven; la tendencia juvenil es "lo indefinido" porque la apariencia y la experiencia le enseñan que es "mejor" no ser él mismo, no asumir su rol en la historia y en la sociedad. El descubrimiento de lo diferente es exigencia para una identidad definida. La cuestión es económica, psicológica, teologal y pedagógica. No hay personalidad definida sin identidad. Supone, incluso, claridad con respecto a los diferentes modos de ser ciudadano. 
d) Colaborar para que el joven sea "juventud", esto es, "joven organizado. Es en la organización juvenil donde se van haciendo protagonistas. Una buena organización es una forma más ágil, más completa, más colectiva de formar personalidades, descubriendo en sus compromisos grupales e institucionales lo que significa "vocación cristiana", lo que significa servicio, ejercicio de poder. En la organización se cultiva el constructor de comunidades, esto es, la formación de una persona, de un joven que aprende lo que es "política". Eso vale, también, para los que pretenden una vocación más "religiosa". Un buen sacerdote, un buen religioso, una buena religiosa es y debe ser política, entender de organización. Siempre afirmamos la "formación en la acción"; lamentamos una juventud desarticulada. Por eso, hablando de vocacionalidad, estamos desarrollando la idea de que hay necesidad de ser político. Hay falta, incluso, en los seminarios y en la vida religiosa de la presencia del político y del ejercicio del protagonismo. Tal vez porque nos hicieron creer que la organización no es importante, que lo político es peligroso, que el protagonismo solamente trae problemas.

e) Garantizar, madurar, incrementar un buen acompañamiento. Ni el adulto ni el joven son felices aisladamente. La sabiduría está en la complementariedad. Si para el adulto el joven es el sacramento de la novedad, para el joven el adulto debe ser el sacramento de la sabiduría de vida. No significa que el adulto no es sacramento; no significa que el joven no tenga sabiduría. En el despertar del joven para la vocacionalidad está todo lo que significa ser un buen acompañante y un feliz acompañado. Eso vale para todos los niveles: personal, grupal, persona con o sin proyecto de vida definido. Una de las carencias más fuertes en medio de la juventud comprometida en grupos es la ausencia de asesores que sean, realmente, acompañantes, que no estén allí para "mandar" o "decidir" sino para estar "junto con", escuchar, sugerir, desafiar, pelear... El protagonismo juvenil no tiene sentido para ser el 'del contra'; tiene sentido para afirmarse como persona, sujeto, dueño de su vida. 


\section{C) Dos instrumentos}

Es importante, por eso, en la presentación de la vocacionalidad al joven una postura pedagógica decidida que respecte y realice las opciones pedagógicas descritas. Con esa postura hay instrumentos pedagógicos que pueden ayudar mucho en este proceso. Resaltamos dos: la revisión de vida y de practica y la elaboración del proyecto de vida.

La revisión de vida y de práctica, un tanto olvidada, es una herencia feliz de la Acción Católica Especializada. No es una mera consecuencia del método ver-juzgar-actuar, es la vivencia de un estilo de vida resultante, fruto de una aplicación acertada de este método. La revisión de vida es algo que necesita ser redescubierto por los grupos juveniles, por los grupos de "vocacionados", por los asesores/as, por todos los que se arriesgan a vivir la radicalidad del Evangelio en el mundo, la radicalidad de lo comunitario y la radicalidad del discernimiento. Es un instrumento que nos ayuda a descubrir, en comunidad, nuestra vocacionalidad.

Otro instrumento, más actual y más urgente es la elaboración y la progresiva vivencia, por parte de las personas, del Proyecto de Vida. Una de las maneras de afrontar la despersonalización sistemática del modelo neoliberal es la introducción sistemática en los grupos juveniles, en las instituciones religiosas, en la formación de liderazgos de la elaboración de este Proyecto Personal de Vida. Sobre eso ya hemos hablado, pero considero fundamental retomar el tema tratándose de despertar la vocacionalidad en la juventud de hoy. Hacen falta en la Iglesia de hoy, en las instituciones religiosas de hoy, en los liderazgos de hoy personas con proyecto de vida definido. Se trata de que nos convenzamos de que la felicidad es algo que es don pero que igualmente es conquista. Son necesarios instrumentos que nos lleven a la radicalidad porque los cuestionamientos que el cambio de paradigmas nos presentan son radicales. Hay aspectos de la posmodernidad que no deben ser encarados como una fatalidad; hay aspectos de la vivencia del cristianismo que esperan ser profundizados. No se toleran ciertas mediocridades vivenciales. Esto es exigencia de la vocación que nos ha sido dada de celebrantes del mundo, de profetas y constructores de comunidad. 


\section{Conclusión}

Tratándose de despertar la vocacionalidad en el mundo juvenil el desafío viene de varios campos. He insistido en el mundo de creatividad, esto es, de la comunicación; en el mundo del testimonio, esto es, de la vivencia; en el mundo de la propuesta, esto es, de la lectura global e inteligente de ser felices en la historia; en el mundo de la radicalidad evangélica que nos lleva al mundo teológico y teologal. Por eso la vocacionalidad es y debe ser una buena noticia que es importante despertar en la sociedad y en el joven de hoy. 